\title{
High Milk Lipase Activity Associated with Breast Milk Jaundice
}

\author{
- RONALD L. POLAND, ${ }^{(36)}$ GARY E. SCHULTZ. AND GAYATRI GARG \\ From the Department of Pediatrics, Wayne State University School of Medicine and the Children's Hospital of \\ Michigan, Detroit, Michigan, USA
}

\begin{abstract}
Summary
Human milk samples that inhibit bilirubin-UDP-glucuronyl transferase (UDPGT) activity in vitro have been associated with prolonged unconjugated hyperbilirubinemia in newborn infants. We measured the concentrations of nonesterified fatty acids (total and individual fatty acids), total fat and protein, and lipase activities (with and without bile salt stimulation) in milk samples from two groups of women. Women whose infants had prolonged unconjugated hyperbilirubinemia and whose milk inhibited the activity of UDPGT were in the first group $(N=9)$. Volunteers with healthy infants acted as controls.

Inhibitory milk contained significantly more nonesterified fatty acids (total, palmitic, and oleic) than did controls. Fat and protein concentrations and bile salt-stimulated lipase activities were similar in the two groups. Unstimulated lipase activity was higher in the inhibitory milks $\left(11.9 \pm 0.8 \mathrm{mM} \cdot \mathrm{min}^{-1} \cdot \mathrm{ml}^{-1}\right)$ than in the controls $\left(6.0 \pm 0.2 \mathrm{mM} \cdot \mathrm{min}^{-1} \cdot \mathrm{ml}^{-1}\right)(P<0.01)$. The specific activity $\left(\mathrm{mM} \cdot \mathrm{min}^{-1} \cdot \mathrm{mg}\right.$ protein $\left.{ }^{-1}\right)$ of unstimulated lipase was also significantly higher in the inhibitory milks $(P<0.0001)$.

The high nonesterified fatty acid levels in inhibitory milks is accounted for by the elevated unstimulated lipase activities. How these circumstances lead to jaundice in the infants remains to be shown.
\end{abstract}

\section{Speculation}

The strong association between high unstimulated lipase activity in human milk and the syndrome of breast milk jaundice leads us to conclude that fat digestion and absorption may have an important effect on the metabolism of bilirubin in newborn infants. Further study of the influence of the digestive process on the absorption and further metabolism of dietary lipid in neonates may help to illuminate the relationship between lipid metabolism and neonatal hyperbilirubinemia.

Breast milk jaundice was described by Arias et al. (3) and Gartner and Arias $(1,5)$ as a syndrome of prolonged neonatal unconjugated hyperbilirubinemia related to the ingestion of certain abnormal human milks. Arias et al. (4) found that these human milks inhibited hepatic bilirubin-UDP-glucuronyl transferase (UDPGT) in vitro and identified the inhibitor as $3 \alpha, 20 \beta$ pregnanediol. They also reported that oral administration of 1 $\mathrm{mg} /$ day of the purified steroid to infants was associated with elevated serum bilirubin levels (2). One other report (21) identified the same pregnanediol in five milk samples associated with the same syndrome.

The clinical syndrome has been described in subsequent reports $(10,26,32)$. Two other laboratories, however, have not been able to find $3 \alpha, 20 \beta$-pregnanediol in milk samples from women with affected infants $(27,29)$. Ramos et al. (29) reported that oral administration of $3 \alpha, 20 \beta$-pregnanediol to infants elevated the mean serum bilirubin less than $0.5 \mathrm{mg} / \mathrm{dl}$, an increment within the limits of experimental error and not statistically significant.
Subsequently, pregnanediol isomers have been found not to inhibit UDPGT, but rather to inhibit release of conjugated bilirubin from the liver cell $(6,17)$, a mechanism that could only lead to conjugated hyperbilirubinemia.

Other groups of investigators have searched for alternative in vitro inhibitors of hepatic UDPGT $(5,23)$. Each has independently identified free fatty acids as in the in vitro inhibitor.

We studied milk samples from mothers of infants with the clinical syndrome of breast milk jaundice and compared them with milk samples of healthy control volunteers to investigate further the cause of breast milk jaundice. Our studies confirm those cited above $(5,22,23)$ and, in addition, identify the source of excess non-esterified fatty acids in the inhibitory milks.

\section{MATERIALS AND METHODS}

Human milk samples were obtained from two groups of women. The first group consisted of women whose infants had prolonged unconjugated hyperbilirubinemia (serum indirect-reacting bilirubin $>10 \mathrm{mg} / \mathrm{dl}$ after 7 days of age) without evidence of disease other than breast milk jaundice $(N=9)$. These women were referred to our laboratory by their physicians in the second to fourth wk of lactation. Standard laboratory investigation of the prolonged neonatal jaundice (28) was negative, and temporary cessation of breast-feeding was associated with a fall in serum bilirubin concentration in their infants. The second group of women (control group, $N=130$ ), delivered at Hutzel Hospital of Detroit and elected to breast-feed their infants. None of the infants in the control group had prolonged jaundice. Control mothers volunteered a 1 to $2 \mathrm{cc}$ milk sample for assay on the third or fourth day of lactation. An additional five volunteers submitted three to five milk samples each, either during the 7-day period of confinement postcesarean section or over a 4- to 5-wk period postpartum. Milk samples were expressed manually and stored in glass containers at $4^{\circ} \mathrm{C}$ for a maximum of $6 \mathrm{hr}$. Some milk samples were stored for a maximum of 3 days at $-20^{\circ} \mathrm{C}$. These storage conditions were found not to alter appreciably any of the enzymatic assay measures.

Milk samples were assayed in vitro for inhibition of UDPGT activity by the method standardized by Strebel and Odel (33). UDPGT was partially purified from Wistar rat liver homogenate by differential centrifugation. UDPGT activity was measured in the microsomal fraction using uridine diphosphoglucuronic acid and crystalline bilirubin as substrates with uridine diphospho- $N$ actylglucosamine added to increase enzyme activity. Whole milk or milk fractions $(0.1 \mathrm{ml})$ were added to $0.64 \mathrm{ml}$ of an enzyme: substrate:buffer mixture. Percentage of inhibition of enzyme activity by the milk was calculated relative to the activity obtained with $0.1 \mathrm{ml}$ of $0.15 \mathrm{M} \mathrm{KCl}$ added to the UDPGT assay instead of milk. In addition, serial dilutions of three inhibitory milks were assayed for their effect on UDPGT activity.

Six inhibitory and six noninhibitory milk samples were assayed also for nonesterified fatty acid levels using a method derived from the copper chelation method of Falholt et al. (11). Relative amounts of medium and long-chain saturated and unsaturated 
fatty acids in the same milk samples were determined by gas chromatography of methylated fatty acid esters (13).

Lipase activity was measured using a modification of the method of Hernell and Olivecrona (19). Tributyrin $(0.25 \mathrm{ml})$ was preincubated $15 \mathrm{~min}$ at $37^{\circ} \mathrm{C}$ in $7.25 \mathrm{ml}$ of $0.154 \mathrm{M} \mathrm{NaCl}$ under a stream of nitrogen and with constant stirring. Then, $20 \mu \mathrm{l}$ of milk were added, and the mixture was maintained at $\mathrm{pH} 7.5$ with $0.002 \mathrm{~N} \mathrm{NaOH}$ delivered via an automatic microburette. The rate of $\mathrm{NaOH}$ addition corresponded to the rate of butyric acid release from tributyrin. The bile salt-stimulated lipase activity of each milk sample was measured using sodium taurocholate $(3 \mathrm{mM})$ and only $5 \mu \mathrm{l}$ of milk to compensate for the increase in lipase activity due to the presence of bile salt.

Total milk protein and total fat were analyzed using the methods of Nakai and Le (25) without modification.

The Student $t$ test was used with Welch's approximation formula corrected for degrees of freedom because of the disparity between the group sizes and variances (30). All measured values are expressed \pm the standard error of the mean. Linear regression and correlation coefficient were calculated using standard formulae (30)

\section{RESULTS}

The addition of inhibitory milk $(N=9)$ to the UDPGT assay $(13.5 \% \mathrm{v} / \mathrm{v})$ reduced the activity of rat liver UDPGT to $8.1 \pm 2.9 \%$ of control activity $(244 \pm 30 \mu \mathrm{g}$ of bilirubin conjugated per $\mathrm{g}$ liver per $30 \mathrm{~min}$ ). On the other hand, UDPGT activity was stimulated $(107.7 \pm 1.8 \%)$ when milk from control women $(N=55)$ was added. When serial dilutions of inhibitory milk samples were tested in the UDPGT assay, less and less inhibition was seen as the milk samples were diluted. At the highest dilutions of inhibitory milks, UDPGT activity was stimulated (Fig. 1). Oleic acid alone is reported to have similar effects on UDPGT activity (17).

The results of the gas chromatography comparing medium- and long-chain fatty acids $\left(\mathrm{C}_{12.0}-\mathrm{C}_{18.3}\right)$ for six each of inhibitory and noninhibitory milk samples is summarized in Table 1. Each of the fatty acid concentrations in the six inhibitory milk samples was higher than that in the six control samples with the total, oleic, and palmitic acids significantly elevated $(P<0.05)$.

Total protein and total fat concentrations in the two populations of milk samples were not significantly different (Table 2).

The comparison of unstimulated and stimulated lipase activities

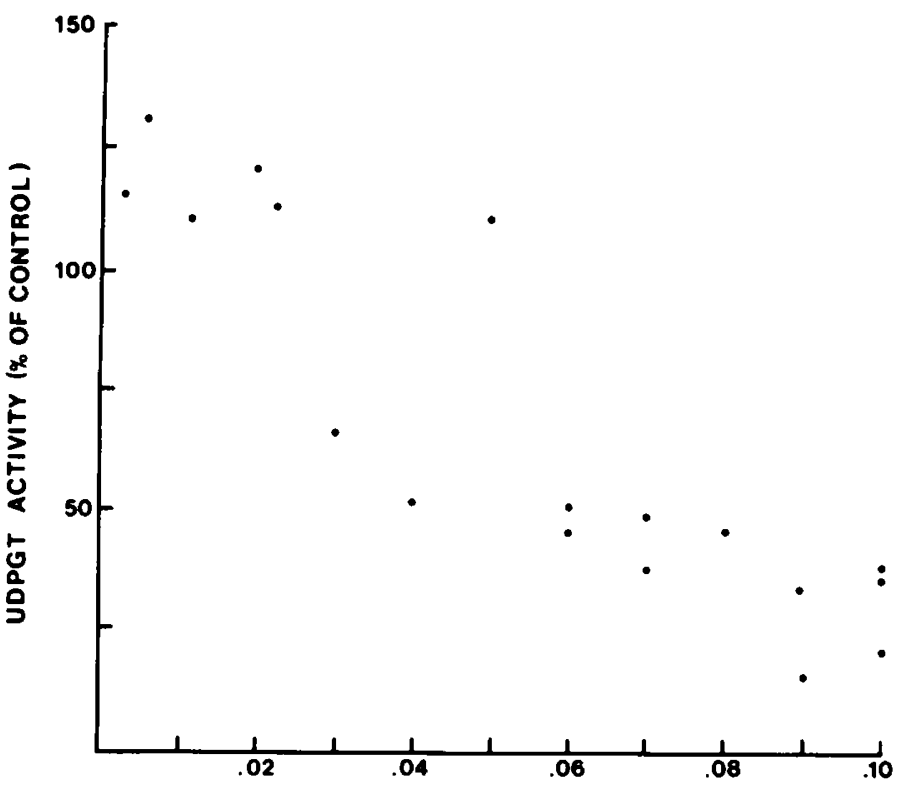

VOLUME OF INHIBITORY MILK ADDED ( $\mathrm{ml}$.)

Fig. 1. Combined results of experiments with three inhibitory milk samples.
Table 1. Free fatty acid concentrations in inhibitory and noninhibitory milks ( $\mathrm{mM}$ )

\begin{tabular}{lccc}
\hline \begin{tabular}{c} 
Free \\
fatty \\
\multicolumn{1}{c}{ acids }
\end{tabular} & $\begin{array}{c}\text { Inhibitory } \\
(N=5)\end{array}$ & $\begin{array}{c}\text { Noninhibitory } \\
(N=5)\end{array}$ \\
\hline Lauric & $\mathrm{C} 12: 0$ & $3.6 \pm 1.3^{1}$ & $1.7 \pm 0.7$ \\
Myristic & $\mathrm{C} 14: 0$ & $3.7 \pm 2.2$ & $1.0 \pm 0.4$ \\
Palmitic & $\mathrm{C} 16: 0^{2}$ & $1.6 \pm 0.2$ & $0.8 \pm 0.3$ \\
Palmitoleic & $\mathrm{C} 16: 1$ & $1.7 \pm 0.3$ & $0.8 \pm 0.4$ \\
Stearic & $\mathrm{C} 18: 0$ & $0.9 \pm 0.1$ & $0.6 \pm 0.2$ \\
Oleic & $\mathrm{C} 18: 1^{2}$ & $10.5 \pm 2.0$ & $4.5 \pm 2.2$ \\
Linoleic & $\mathrm{C} 18: 2$ & $5.0 \pm 1.5$ & $2.0 \pm 0.8$ \\
Linolenic & $\mathrm{C} 18: 3$ & $0.7 \pm 0.3$ & $0.5 \pm 0.2$ \\
& & $27.6 \pm 1.3$ & $11.9 \pm 4.9$ \\
\hline
\end{tabular}

${ }^{\prime}$ Mean \pm S.E.

${ }^{2}$ Differences in free fatty acids significant at the $P<0.05$ level.

in the inhibitory and control milks is summarized in Table 2. Mean lipase activity (unstimulated) of the inhibitory milks was approximately twice that of the mean lipase activity of the control milks $(P<0.01)$. This activity did not change significantly in control samples collected over the first wk of lactation or over the 4- to 5-wk collection periods (Fig. 2). Bile salt-stimulated lipase activity, however, was not significantly higher in the inhibitory milks. The ratio of bile salt-stimulated to unstimulated lipase activity was apparently higher in control milks $(12.5 \pm 0.3)$ than in the inhibitory milks $(8.5 \pm 1.6)$ but not statistically higher $(P$ $>0.1$ ).

The specific activity $\left(\mathrm{mM} \cdot \mathrm{min}^{-1} \cdot \mathrm{mg}\right.$ protein $\left.{ }^{-1}\right)$ of unstimulated lipase was calculated to adjust for changing protein levels occurring during the course of breast feeding. Because protein values were lower in the milks with the highest unstimulated lipase activities, the difference in the mean specific activities of unstimulated lipase in the two populations was highly significant $(P<$ 0.0001 ) with no overlap of individual values in the two groups.

\section{DISCUSSION}

We have confirmed that milk samples of women with infants exhibiting the clinical syndrome of breast milk jaundice inhibit (and normal milks enhance) the activity of UDPGT in vitro. Chemical comparison of normal and inhibitory milk samples reveals that nonesterified fatty acid (NEFA) is the in vitro inhibitor. Inhibitory milk samples contained significantly more NEFA than did controls in our study, and NEFA is a re ognized inhibitor of UDPGT. The array of free fatty acids in abnor mal milk samples was similar to that found in the esters of normal human milk triglycerides.

We attribute the high NEFA levels to the hydrolysis of the milk triglycerides by abnormally high lipase activity. Others have found that concentrations of NEFA in abnormal milks and their UDPGT-inhibitory activity increase with storage time even at $4^{\circ} \mathrm{C}(9,22,23)$. Furthermore, fresh samples of milk from women with breast milk jaundice infants have little or no UDPGTinhibitory capacity when heated immediately to $56^{\circ} \mathrm{C}(12,23)$. Our data are consistent with these observations. Our measurements of the unstimulated lipase activities of inhibitory milk samples were clearly higher than that of controls.

At least two lipases have been described in human milk and in milk from other primates (18). About $95 \%$ of lipase activity in milk is due to a bile salt-stimulated enzyme which is found in the whey protein fraction but has not been purified extensively (18). Most of the remaining lipolytic activity is contributed by a serumstimulated lipase (probably lipoprotein lipase). The serum-stimulated milk lipase may not be active in vitro $(18,19)$.

The action of bile salt-stimulated lipase like lingual lipase (16) appears to result in the hydrolysis of triglycerides to glycerol and free fatty acids $(18,20)$. Pancreatic lipase differs from bile salt- 
Table 2

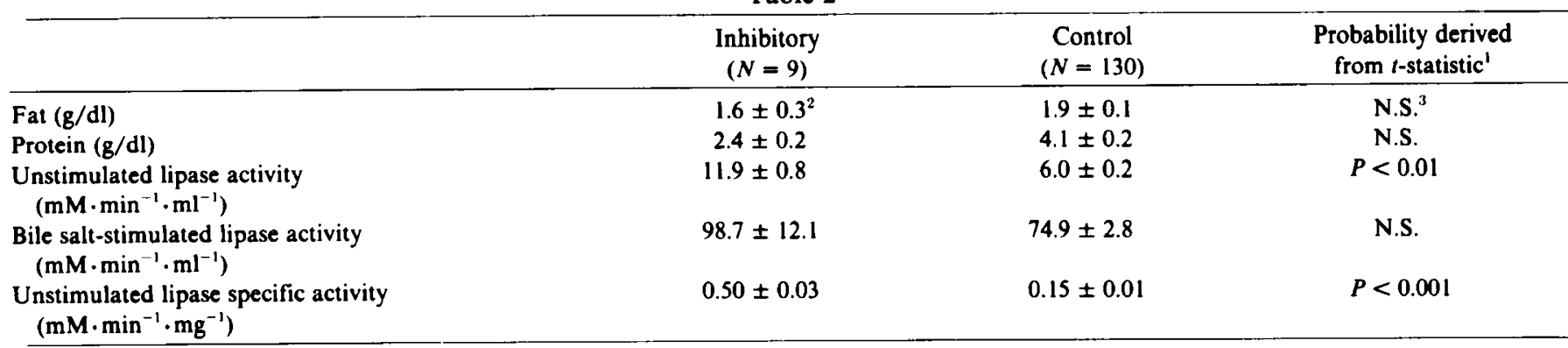

${ }^{1}$ All $t$ values are approximate using Welch's approximation formula and corrected for degrees of freedom.

${ }^{2}$ Mean \pm S.E.

${ }^{3}$ N.S., not significant.

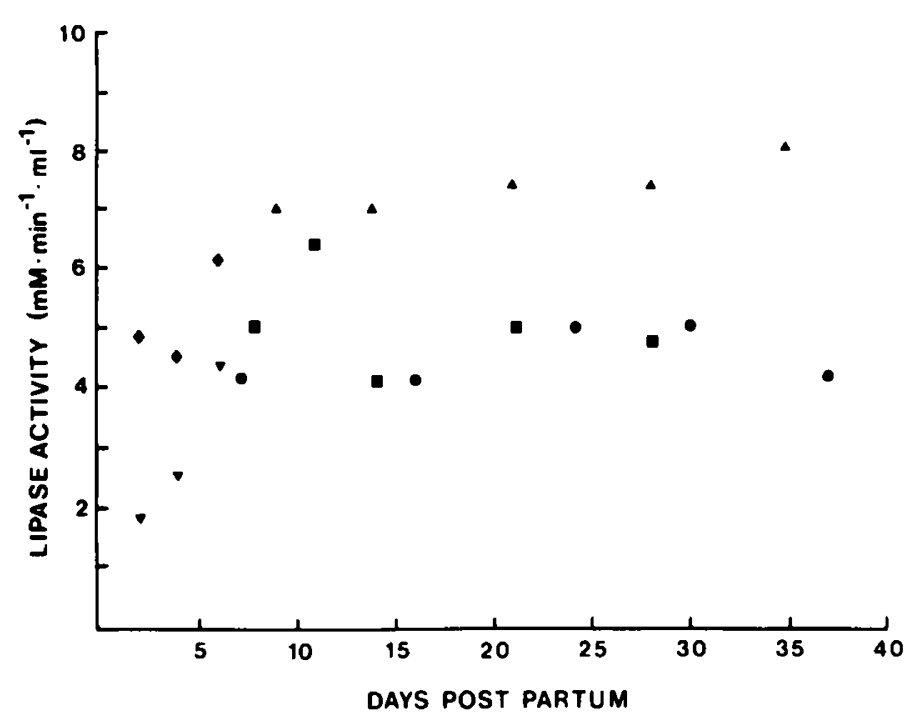

Fig. 2. Results of longitudinal studies of unstimulated lipase activities in milk samples from five volunteers $(\bullet,, \nabla, \boldsymbol{\nabla}, \Delta)$.

stimulated lipase in that the pancreatic enzyme hydrolyzes triglycerides to 2-monoglyceride and free fatty acids primarily. The pancreatic enzyme is weakly active with 2 -monoglyceride as its substrate. Bile salt-stimulated lipase activity is much more likely to yield free glycerol than is pancreatic lipase.

Bile salt-stimulated lipase is resistant to acid-pepsin treatment and to the action of neutral trypsin (20). We measured lipase activities (stimulated by bile salt and unstimulated), total protein, and fat in 130 normal human milk samples in nine UDPGTinhibitory milks from women with infants who had prolonged unconjugated hyperbilirubinemia. The two populations were similar in protein and fat concentrations and in bile salt-stimulated lipase activities. They differed significantly in unstimulated lipase activities and in the specific activities of unstimulated lipase. The ratios of bile salt-stimulated to unstimulated lipase activities were lower in the abnormal milks, but the difference between means were not statistically significant.

The somewhat higher protein values in the control milks can be explained by the time of collection (third to fourth days) as compared to the time of collection of the inhibitory milks (eighth to 20th days). Transitional milk is known to be higher in protein than mature milk (24). Our longitudinal studies of milk samples from five control mothers showed that the activity of unstimulated lipase changes insignificantly over the first 4 to $5 \mathrm{wk}$ of lactation. The maturity of the milk, therefore, does not seem to account for the significant difference in unstimulated lipase activity that we found.

No experimental evidence has been developed to explain the mechanisms responsible for the production of hyperbilirubinemia in infants who are fed milk with the variant lipase activity. We suggest the following hypothetical mechanisms which are consistent with the known facts.

Milk from normal women contains little lipase activity in the absence of bile salts. Most of the triglycerides in the milk are hydrolyzed normally in the upper small intestine by human milk bile salt-stimulated lipase and pancreatic lipase. Pancreatic lipase hydrolyzes fatty acids from triglycerides and diglycerides well but is only weakly active with 2 -monoglyceride as its substrate (20). Human milk bile salt-stimulated lipase hydrolyzes readily all three fatty acids from triglyceride producing free glycerol. Normally, a considerable amount of glycerol backbone from milk triglycerides is available for resynthesis of triglycerides in the intestinal epithelium. Most of the triglycerides resynthesized there enter the lymphatics.

We propose that human milk with high lipase activity in the absence of bile salt-stimulation (abnormal milk) may initiate a markedly different digestive process. The triglycerides in such milk would be hydrolyzed extensively by the variant lipase before they reach the upper small intestine. We estimate from our studies that the milk triglycerides can be completely hydrolyzed to glycerol and fatty acids in approximately $30 \mathrm{~min}$ at near-neutral $\mathrm{pH}$. Gastric acid production is low in neonates (1) and postprandial $\mathrm{pH}$ values above 6.0 are common (14). Extensive predigestion of triglycerides would result in high levels of free fatty acids in the lumen of the upper small bowel. Glycerol can be absorbed rapidly in the stomach as well as the duodenum (34) and may be assimilated long before the bulk of the fatty acids is absorbed. Another source of glycerol backbone for the nonesterified fatty acids would then be necessary. Saunders and Dawson (31) found that less than one-third of labeled glycerol was recovered as triglycerides in lymph after feeding an oleic acid:glycerol:taurocholate mixture to adult rats.

Glucose may be an alternate source of glycerol backbone for the resynthesis of triglycerides in the intestinal epithelium, but newborn infants may have difficulty in utilizing this alternative. Buchs and Favarger (8) found about $25 \%$ of reconstructed triglycerides from rat intestine had glycerol backbones derived from circulating glucose. Glycerol phosphate and dihydroxyacetone phosphate (products of glycolysis) have each been suggested as substrates for the resynthesis of triglycerides in the intestine (7). However, enzymes in this pathway such as monoglyceride acyltransferase, acyl-CoA synthetase, and diglyceride acyltransferase are low in specific activity in fetal animals as well as starving animals. These enzymes can be induced to higher specific activity by high-fat diets. We have no reason to believe, therefore, that newborn infants would have high specific activities of these enzymes in their intestinal epithelia.

If (1) the glycerol freed from milk triglycerides became unavailable because of early digestion by an abnormally high unstimulated lipase activity and rapid absorption, or (2) the intestinal epithelium is unable to produce enough glycerol backbone from glycolysis to re-esterify all the fatty acids absorbed, or (3) the intestinal epithelium is unable to keep up with the actual esterification of absorbed fatty acids due to a relative deficiency of fatty 
acyl-CoA formation, then the fatty acids may diffuse into the portal circulation in significant quantities. The livers of such infants may be presented with a fatty acid load which might saturate the $Z$ protein carrier system (12) or directly inhibit the activity of UDPGT. Either of the last two mechanisms would lead to prolonged unconjugated hyperbilirubinemia in the infant.

In summary, there is a strong association between breast milk jaundice and an inhibitor of UDPGT activity in vitro. The inhibitor is nonesterified fatty acids which appears in the abnormal milk in excess quantities due to the action of an abnormal lipolytic activity. Whether this defect is genetically determined or due to some "stimulant" of lipase activity and how it leads to prolonged, unconjugated hyperbilirubinemia all remain to be investigated.

\section{REFERENCES AND NOTES}

1. Agunod, M., Yamaguchi, N., Lopez, R., Luhby, A. L., and Glass, G. B. Correlative study of hydrochloric acid, pepsin and intrinsic factor secretion in newborns and infants. Am. J. Dig. Dis., 14: 400 (1969)

2. Arias, I. M., and Gartner, L. M.: Production of unconjugated hyperbilirubinemia in full-term newborn infants following administration of pregnane-3 (alpha), 20 (beta)-diol. Nature (Lond.), 203: 1292 (1964).

3. Arias, I. M., Gartner, D. M., Seifter, S., and Furman, M.: Neonatal unconjugated hyperbilirubinemia associated with breast-feeding and a factor in milk that inhibits glucuronide formation in vitro. J. Clin. Invest., 42: 913 (1963).

4. Arias, 1. M., Gartner, L. M., Seifter, S., and Furman, M.: Prolonged neonatal unconjugated hyperbilirubinemia associated with breast feeding and a steroid, pregnane-3 (alpha), 20 (beta)-diol, in maternal milk that inhibits glucuronide formation in vitro. J. Clin. Invest., 43: 2037 (1964).

5. Bevan, B. R., and Holton, J. B.: Inhibition of bilirubin conjugation in rat liver slices by free fatty acids with relevance to the problem of breast milk jaundice. Clin, Chim. Acta, 4l: 101 (1972).

6. Bevan, B. R., Holton, J. B., and Lathe, G. H.: The effect of pregnanediol and pregnanediol glucuronide on bilirubin conjugation by rat liver slices. Clin. Sci. (Oxf.), 29: 353 (1965).

7. Brindley, D. N.: Absorption and transport of lipids in the small intestine. In M. Kramer, F. Lauterbach: Intestinal Permeation. pp. 350-362. (Excerpta Medica, Amsterdam, 1977).

8. Buchs, A., and Favarger, P.: Research on the metabolism of lipid glycerol. Helv. Physiol. Pharmacol. Acta, 17: 365 (1959).

9. Cole, A. P., and Hargreaves, T.: Conjugation inhibitors and early neonata hyperbilirubinemia. Arch. Dis. Child., 47: 415 (1972).

10. Done, A. K., and Temple, A. R.: Breast milk inhibition of glucuronyl transferase: its measurement and clinical correlates. Indian J. Med. Surg., 36: 123 (1971).

11. Falholt, K., Lund, B., and Falholt, W.: An easy colorimetric micro-method for routine determination of free fatty acids in plasma. Clin. Chim. Acta, 46: 105 (1973).

12. Foliot, A., Ploussard, J. P., Housset, E., Christoforov, B., Luzeau, R., and Odievre, M.: Breast milk jaundice: in vitro inhibition of rat liver bilirubin-uridine diphosphate glucuronyltransferase activity and $\mathbf{Z}$ protein-bromosulfophtalein binding by human breast milk. Pediatr. Res., 10: 594 (1976).

13. Fosbrooke, A. S., and Tamir, I.: A modified method for the preparation of methyl esters of a mixture of medium-chain and long-chain fatty acids. Clin.

Copyright (C) 1980 International Pediatric Research Foundation, Inc. $0031-3998 / 80 / 1412-1328 \$ 02.00 / 0$
Chim. Acta, 20: 517 (1968)

14. Fredrikzon, B., Hernell, O., Blackberg, L., and Olivecrana, T.: Bile salt-stimulated lipase in human milk: evidence of activity in vivo and of a role in the digestion of milk retinol esters. Pediatr. Res., 12: 1048 (1978).

15. Gartner, L. M., and Arias, I. M.: Studies of prolonged neonatal jaundice in the breast-fed infant. J. Pediatr., 68 : 54 (1966).

16. Hamosh, M., Sivasubramanian, K. N., Salzman-Mann, C., and Hamosh, P.: Fat digestion in the stomach of premature infants. J. Pediatr., 93: 674 (1978).

17. Hargreaves, T., and Piper, R. F.: Breast milk jaundice: effect of inhibitory breast

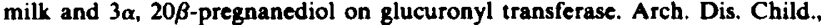
46: 195 (1971).

18. Hernell, O.: Human milk lipases. III. Physiological implications of the bile saltstimulated lipase. Eur. J. Clin. Invest., 5: 267 (1975).

19. Hernell, O., and Olivecrona, T.: Human milk lipase. I. Serum-stimulated lipase. J. Lipid. Res., 15: 367 (1974).

20. Hernell, O., and Olivecrona, T.: Human milk lipases. II. Bile salt-stimulated lipase. Biochim. Biophys. Acta, 369: 234 (1974).

21. Krauer-Mayer, B., Keller, M., and Hottinger, A.: Uber den frauenmilchinduzierten Icterus prolongatus des Neugeborenen. Helv. Paediatr. Acta, 1: 68 (1968).

22. Levillain, R., Odievre, M., Luzeau, R., and Lemonnier, A.: Possibilites d'inhibition de la glucuro-conjugaison de la bilirubine en fonction de la teneur en acides gras libres du lait maternal. Biochim. Biophys. Acta, 264: 538 (1972).

23. Luzeau, R., Levillain, P., Odievre, M., and Lemonnier, A.: Demonstration of a lipolytic activity in human milk that inhibits the glucuroconjugation of bilinbin. Biomedicine (Paris), 21: 258 (1974)

24. Macy, I. G., and Kelly, H. J.: Human milk and cow's milk in infant nutrition In S. K. Kon, A. T. Cowie: Milk: The Mammary Gland and Its Secretion. Vol. 2, pp. 265-304. (Academic Press, Inc., New York, 1961).

25. Nakai, S., and Le, A. C.: Spectrophotometric determination of protein and fat in milk simultaneously. J. Dairy Sci., 53: 276 (1970).

26. Newman, A. J., and Gross, S.: Hyperbilirubinemia in breast-fed infants. Pediatrics, 32: 995 (1963).

27. Odell, G. B.: (personal communication).

28. Poland, R. L., and Ostrea, E. M.: Neonatal hyperbilinubinemia In: M. H. Klaus, A. A. Fanaroff: Care of the high-risk neonate. Ed. 2, pp. 243-266, (W. B. Saunders Co., Philadelphia, 1979).

29. Ramos, A. M., Silverberg, M., and Stern, L.: Pregnanediols and neonatal hyperbilirubinemia. Am. J. Dis. Child., 111: 353 (1966).

30. Remington, R. D., and Schock, M. A.: Statistics with applications to the biological and health sciences. (Prentice-Hall, Inc., Englewood Cliffs, NJ, 1970).

31. Saunders, D. R., and Dawson, A. M.: Studies on the metabolism of glycerol by the small intestine in vitro and in vivo. Biochem. J., 82: 477 (1962).

32. Stiehm, E. R., and Ryan, J.: Breast milk jaundice. Am. J. Dis. Child., 109: 212 (1965).

33. Strebel. L., and Odell, G. B.: Bilirubin uridine diphospho-glucuronyltransferase in rat liver microsomes: genetic variation and maturation. Pediatr. Res., 5: 548 (1971).

34. Wiggins, H. S., and Dawson, A. M.: An evaluation of unabsorbable markers in the study of fat absorption. Gut, 2: 373 (1961).

35. The authors are indebted to Ruth Winkler for the collection of the control milk samples, to E. M. Ostrea for the analysis of fatty acids, to the LaLeche League for their assistance in the longitudinal studies and to V. O'Rourke and P. Averbach for their assistance in preparing the manuscript.

36. Requests for reprints should be addressed to: Ronald L. Poland, M.D., 3901 Beaubien Boulevard, Detroit, MI 48201 (USA)

37. Received for publication October 16, 1979.

38. Accepted for publication March 13, 1980. 